Interação em Psicologia, 2007, 11(1), p. 43-54

\title{
Pré-requisitos da linguagem: Padrões comportamentais na interação criança-acompanhante ${ }^{1}$
}

\author{
Carlos Barbosa Alves de Souza \\ Luciana dos Reis Affonso \\ Universidade Federal do Pará
}

\begin{abstract}
RESUMO
A interação criança-acompanhante é considerada central no processo de aquisição da linguagem. Este estudo procurou identificar e analisar padrões comportamentais (e.g., estratégias de ensino maternas; aquisições cognitivas filiais) estabelecidos nas interações criança-acompanhante durante o primeiro ano de vida da criança. Participaram três crianças (uma menina e dois meninos), todas com dois meses no início do estudo, geralmente acompanhadas pelas mães. Foram filmadas sessões semanais das interações criança-acompanhante. Os resultados mostraram que inicialmente os comportamentos maternos 'adaptar'e 'apontar' e o comportamento filial 'observar' foram os mais emitidos. A partir do quinto mês nota-se que 'apontar', 'aquisições cognitivas' e 'sons' ocorreram com maior freqüência. Além disso, verificou-se que: 1) os 'módulos dinâmicos', 'chorar', 'rir' e 'interação motora' tiveram a maior freqüência; 2) a 'interação protolingüística mais emitida foi 'não-verbal do acompanhante'; e 3) as 'estratégias de ensino', 'apontar', 'adaptar' e 'fornecer feedback' foram as que apresentaram maior freqüência. De maneira geral se observaram covariações entre os comportamentos do acompanhante e os da criança. Estes resultados são discutidos considerando a literatura sobre a interação mãe-criança, os dados anteriores desta linha de pesquisa e os possíveis papéis daqueles padrões comportamentais como pré-requisitos na aquisição da linguagem.
\end{abstract}

Palavras-chave: interações criança-acompanhante; padrões comportamentais; pré-requisitos da linguagem.

\begin{abstract}
Language prerequisites: Behavioral patterns in the infant-caregiver interaction

Infant-caregiver interaction is a fundamental aspect in language acquisition process. The objective of this study was to identify and analyze behavioral patterns (caregiver's teaching strategies; child cognitive acquisitions) established in infant-caregiver interactions during the first year of life. Two boys and one girl participated, all two months of age at the start of the study, usually accompanied by their mothers. Weekly sessions of infant-caregiver interaction were filmed. Results showed that, initially, caregiver behaviors of 'adapting' and 'pointing' and infant behavior 'observing' were most frequent. From the fifth month on, 'pointing', 'cognitive acquisitions' and 'sounds' were more frequent. It was also observed that 1) 'crying', 'laughing and 'motor interaction' were most frequent in the 'dynamic modules'; 2) the most frequent instance of 'protolinguistic interaction' was 'nonverbal of the caregiver'; and 3) the most frequent 'teaching strategies' were 'pointing', 'adapting' and 'giving feedback'. In general, co-variations between caregiver and infant behaviors were observed. Results are discussed in terms of the child-caregiver interaction literature, previous data from this line of investigation and possible roles of those behavioral patterns as prerequisites in language acquisition.
\end{abstract}

Keywords: infant-caregiver interactions; behavioral patterns; language prerequisites.

De um ponto de vista funcional, o conjunto de repertórios denominado 'linguagem' pode ser caracterizado como comportamento convencionalmente estabelecido e mantido pelas conseqüências mediadas pelo grupo social no qual ele ocorre (Brino \& Souza, 2005; Skinner, 1957/1992; Tomasello, 2003)². Desde esta perspectiva, as variáveis explicativas da aquisição e desenvolvimento deste tipo de comportamento devem ser buscadas nas interações do indivíduo com o seu ambiente.

Souza (2001) investigou, em crianças de dois anos de idade, o efeito do simples pareamento de palavras e objetos (sem consequenciações contínuas e imediatas das respostas da criança) sobre os comportamentos 
lingüísticos 'apontar' (emitir uma resposta motora e/ou observacional relacionada a um objeto/evento do mundo), 'nomear' (emitir uma resposta vocal/gestual/ pictórica designando algum objeto/evento do mundo) e 'repetir verbalizações' (emitir uma resposta vocal exata, reduzida, expandida ou combinada). Verificouse que o simples pareamento palavras-objetos facilitou a aprendizagem dos comportamentos de 'apontar' e 'nomear', sendo que o comportamento 'repetir verbalizações’ já existia como uma classe generalizada de respostas nas crianças daquela idade.

Em um estudo longitudinal posterior, Souza (2003) replicou o estudo anterior, mas com crianças entre os sete e os dez meses de idade, para o comportamento de 'apontar', e dos dez aos treze meses para o comportamento de 'nomear'. Os resultados mostraram que o emparelhamento não foi condição suficiente para a aquisição destes comportamentos, sendo, porém, observado o surgimento de respostas de 'olhar-conjunto' (mutual gazing), 'imitação motora e vocal', considerados pré-requisitos na aquisição da 'linguagem'.

De acordo com Souza (2003), estes resultados juntamento com outros sobre a aquisição de repertórios lingüísticos e seus pré-requisitos em crianças com menos de 2 anos de idade (e.g., Schafer \& Plunkett, 1998; Woodward, Markman \& Fitzsimmons, 1994), sugerem que certos padrões comportamentais presentes nas interações criança-acompanhante (e.g., pareamentos palavras-referentes; correções e expansões de respostas protoverbais), podem atuar conjuntamente como pré-requisitos no processo de aquisição de comportamentos lingüísticos. Uma maneira de verificar esta hipótese é estudar as interações criança-acompanhante em situações naturais, durante os primeiros anos de vida, analisando funcionalmente os padrões comportamentais que emergem destas interações, procurando verificar suas possíveis funções de prérequisitos para a aquisição da 'linguagem'. No entanto, poucos estudos têm sido realizados com esta finalidade, e raros enfocando os aspectos funcionais das interações criança-acompanhante (ver Bornstein \& Tamis-LeMonda, 2004; Ribes \& Quintana, 2003; Souza, 2003; Tomasello, 2003).

Moerk, em uma série de estudos (e.g., 1978, 1983, 1990, 1999) re-analisando os dados colhidos por Roger Brown em um estudo longitudinal com três crianças e suas respectivas mães, tem sido um dos poucos autores a abordar a aquisição de comportamentos lingüísticos e de seus pré-requisitos enfocando os aspectos funcionais da interação criança-acompanhante. Moerk (1983), com o objetivo de verificar a influência dos padrões comportamentais que emergem na interação mãe-criança sobre a aquisição da linguagem, re-analisou os dados de Roger Brown, verificando nas interações mãe-criança estratégias filiais de aprendizagem e técnicas maternas de ensino da linguagem. Nesta re-análise, de maneira contrária às conclusões de Brown, Moerk observou nas diferentes dinâmicas da interação mãe-criança a importância das relações contingenciais como processo na aquisição da linguagem.

Moerk (1990) concluiu em uma análise das contingências de três-termos nas interações verbais mãecriança, que estas apresentavam dois padrões: correção ou reforçamento. A mãe, depois de apresentar um estímulo à criança e desta responder, a corrigia caso a resposta não fosse adequada, ou a reforçava caso a resposta fosse correta. Em um outro estudo, Moerk (1999) realizou uma detalhada análise seqüencial dos comportamentos verbais na interação mãe-criança, procurando detectar nesta relações causais entre o input verbal apresentado à criança e o seu repertório verbal. Verificou-se a ocorrência de estímulos múltiplos (verbais e não-verbais) interferindo na aquisição das respostas verbais, indicando que causas múltiplas (e.g., reforçamento, generalização, variáveis motivacionais) parece ser a regra na aquisição da linguagem.

Moerk (1999) verificou também, através de análises seqüenciais de contingências, que elas não precisam ser necessariamente contíguas (a emissão da resposta ocorrer logo após a presença do estímulo e/ou a conseqüência logo após a resposta). Elas podem ocorrer por semelhanças morfológicas ou funcionais entre os antecedentes e as conseqüências que fazem parte delas; ou seja, as contingências podem implicar intervalos curtos ou relativamente longos, sem que ocorra nenhuma interferência na relação de dependência que há nelas.

Ribes e Quintana (2003), também baseando-se nas interações cuidador-criança, apresentaram uma proposta de estudado da aquisição da linguagem desde uma perspectiva funcional. Estes autores sugeriram um conjunto de aspectos interativos a serem observados na tentativa de melhor compreender a aquisição da linguagem, entre eles: 1) 'interações lingüísticas e protolingüísticas; 2) 'aquisições cognitivas' da criança; 3) 'dinâmicas modulatórias das interações'; 4) 'modos de episódios lingüísticos e protolingüísticos’; e 5) 'estratégias de ensino’ do acompanhante.

As ‘interações protolingüísticas' podem ser definidas em quatro categorias a partir de quem inicia a interação: 1) não-verbais do acompanhante, 2) nãoverbais da criança, 3) não-verbais do acompanhante 
com respostas verbais do mesmo sobre a interação, e 4) não-verbais da criança com respostas verbais do acompanhante sobre a interação. Estas interações caracterizam os padrões comportamentais definidos como protoconversações (Lock, 2004; Trevarthen \& Aitken, 2001), sendo que a característica 'não-verbal' das categorias implica um padrão de respostas vocais de um dos membros da díade (e.g., sons vocálicos ou consonantais repetidos, ecolalias silábicas ou de palavras) que não constitui os elementos fonológicos usados consistentemente em uma comunidade verbal.

As 'aquisições cognitivas' são comportamentos das crianças que resultam em respostas motoras (ou de orientação) e em respostas verbais (com morfologias vocais e não-vocais) as propriedades funcionais do seu ambiente. Estes comportamentos foram divididos em nove categorias, sendo que uma apresenta subcategoria: 1) atender; 2) calcular; 3) discriminar; 4) acompanhar instruções; 5) identificar: a) nãoverbalmente: indicando, escolhendo, manipulando e orientando; b) verbalmente: designando (nomeando, denotando e/ou assinalando); e descrevendo (especificando, representando e/ou estipulando); 6) imaginar; 7) lembrar; 8) reproduzir e 9) transcrever.

Os 'módulos dinâmicos' são comportamentos que modulam a duração e ritmo das interações, no sentido de que suas ocorrências podem determinar o início e o final das interações e velocidade (ritmo) dos intercâmbios comportamentais (criança-acompanhante) que acontecem nela. Nove categorias foram propostas: 1) ações motoras; 2) comportamentos afetivos; 3) interação motora; 4) resposta verbal; 5) choro; 6) riso; 7) grito; 8) gesticulação (ativa ou reativa); e 9) ações não-correspondidas.

Os 'modos de episódios lingüísticos e protolingüisticos' indicam os modos (ativo x reativo) e a modalidades nas quais as interações lingüísticas e protolingüisticos podem ocorrer. São propostas quatro categorias, cada uma com sub-categorias: 1. 'Modo ativo': a) gesticular e indicar; b) falar; c) escrever; 2. 'Modo reativo': a) observar; b) escutar; c) ler; 3. 'Episódios múltiplos' (duas sub-categorias no modo ativo ou no reativo): e.g., gesticular e falar; e 4. 'Episódios combinados' (duas sub-categorias nos modos ativo e reativo): e.g., gesticular e observar.

As 'estratégias de ensino' são comportamentos emitidos pelo acompanhante que antecedem ou conseqüenciam o comportamento da criança. Estas estratégias foram divididas em quinze categorias: expandir, substituir, completar, fornecer feedback, adaptar, associar, encadear, modelar, instigar, perguntar, ordenar, instruir, exemplificar, apontar e dar instruções. A única categoria que possui sub-categorias é 'fornecer feedback', que pode ser: repetir, corrigir, recompensar, elogiar, aprovar, encorajar a continuar, punir e interromper.

Com base nas categorias e conclusões de Souza (2001, 2003), Ribes e Quintana (2003) e Moerk (1978, 1983, 1990, 1999), a presente pesquisa procurou identificar e analisar alguns padrões comportamentais (e.g., 'estratégias de ensino maternas', 'aquisições cognitivas' filiais, 'interações protolingüísticas') estabelecidos nas interações criança-acompanhante durante o primeiro ano de vida da criança, avaliando os possíveis papéis daqueles padrões como prérequisitos para aquisição da 'linguagem'.

\section{MÉTODO}

Participantes: Participaram do estudo três crianças, dois meninos e uma menina, todas com dois meses de idade no início do estudo, sem problemas de saúde, filhos únicos de famílias de classe média, tendo como principal acompanhante a própria mãe. Os responsáveis pelas crianças assinaram um termo de consentimento livre e esclarecido (conforme os critérios estabelecidos na resolução 196/96 do Conselho Nacional de Saúde), autorizando o desenvolvimento do estudo.

Equipamento: Foi utilizada uma câmera de vídeo (8 mm), um tripé e os brinquedos de cada criança (bichos de pelúcia, bonecas, livros etc). Os brinquedos presentes variavam a cada filmagem.

Procedimento: Foi realizada uma sessão por semana, na residência de cada participante, sem dia fixo. Cada sessão possuía um tempo de duração que dependia do momento de interação criança-acompanhante registrado (uma média de 15 minutos por sessão), o qual poderia constar de (a) uma situação de higiene (banho ou troca de fraldas), (b) uma situação na qual a criança estivesse sendo alimentada (através de mamadeira ou seio materno) ou (c) uma situação na qual o acompanhante estivesse brincando com a criança. Deu-se preferência à situação (c), por ser o momento em que a criança mostrava-se mais ativa. No início da sessão, o experimentador ligava a câmera, posicionando-a em um tripé, de modo que registrasse o melhor ângulo frontal da interação, e então, iniciava a filmagem, sem interferir nela. Ao término da mesma, desligava a câmera e desmontava o equipamento.

Análise dos dados: As gravações foram analisadas em intervalos de 1 minuto e transcritas em uma folha de registro. Considerando os possíveis repertórios da criança nesta etapa do desenvolvimento (2-12 meses) 
buscou-se identificar em cada momento da interação do acompanhante com a criança a ocorrência das seguintes categorias comportamentais:

1 - 'Interações protolingüísticas'(a partir de quem inicia a interação): a) não-verbais do acompanhante, b) não-verbais da criança, c) não-verbais do acompanhante com respostas verbais do mesmo sobre a interação, e d) não-verbais da criança com respostas verbais do acompanhante sobre a interação.

2 - 'Aquisições cognitivas’: manipular ou operar um objeto de qualquer maneira mecânica.

4 - 'Modo de episódio protolingüistico’: observar modo reativo.

5 - 'Estratégias de ensino’: adaptar, modelar ações, instigar, apontar e fornecer feedback.

6 - 'Sons': vocalizações da criança compostas por vogais, ou consoantes e vogais padrões do português (portanto, diferentes das vocalizações 'não-verbais' das interações protolingüísticas)

Vale ressaltar que das categorias citadas acima, algumas correspondem a comportamentos da mãe, outras da criança, e algumas são interações de ambas.

Trinta por cento das sessões foram codificadas por dois experimentadores para estabelecer um índice de concordância entre observadores ([Concordâncias /Concordâncias + Discordâncias] x 100) para o regis- tro das categorias analisadas, o qual variou de 89 a $100 \%$.

\section{RESULTADOS}

Foram registradas e analisadas 21 sessões de interação criança-acompanhante do Participante 01 (dos 2 aos 7 meses) e 17 e 15 dos Participantes 2 e 3, respectivamente (dos 2 aos 5 meses aproximadamente).

As figuras a seguir mostram as freqüências acumuladas (em análises minuto a minuto) das categorias emitidas pelas díades dos Participantes 1, 2 e 3 em todas as sessões, com intervalos de aproximadamente 15 minutos correspondendo a uma sessão (uma semana). As Figuras 1, 4 e 7 apresentam os resultados da categoria 'estratégias de ensino'; as Figuras 2, 5 e 8 os resultados de 'módulos dinâmicos' e 'modo de episódio'; e as Figuras 3, 6 e 9 os das categorias 'interações protolingüísticas', 'aquisições cognitivas' e 'sons'.

A Figura 1 apresenta as 'estratégias de ensino' da mesma díade nas 21 sessões. Nota-se que o comportamento materno mais emitido foi "Apontar", seguido de "Adaptar", "Fornecer feedback”, "Modelar ações” e "Instigar", sendo que os três últimos apresentaram freqüências com poucas variações no decorrer das sessões (menores que 50 emissões cada um).

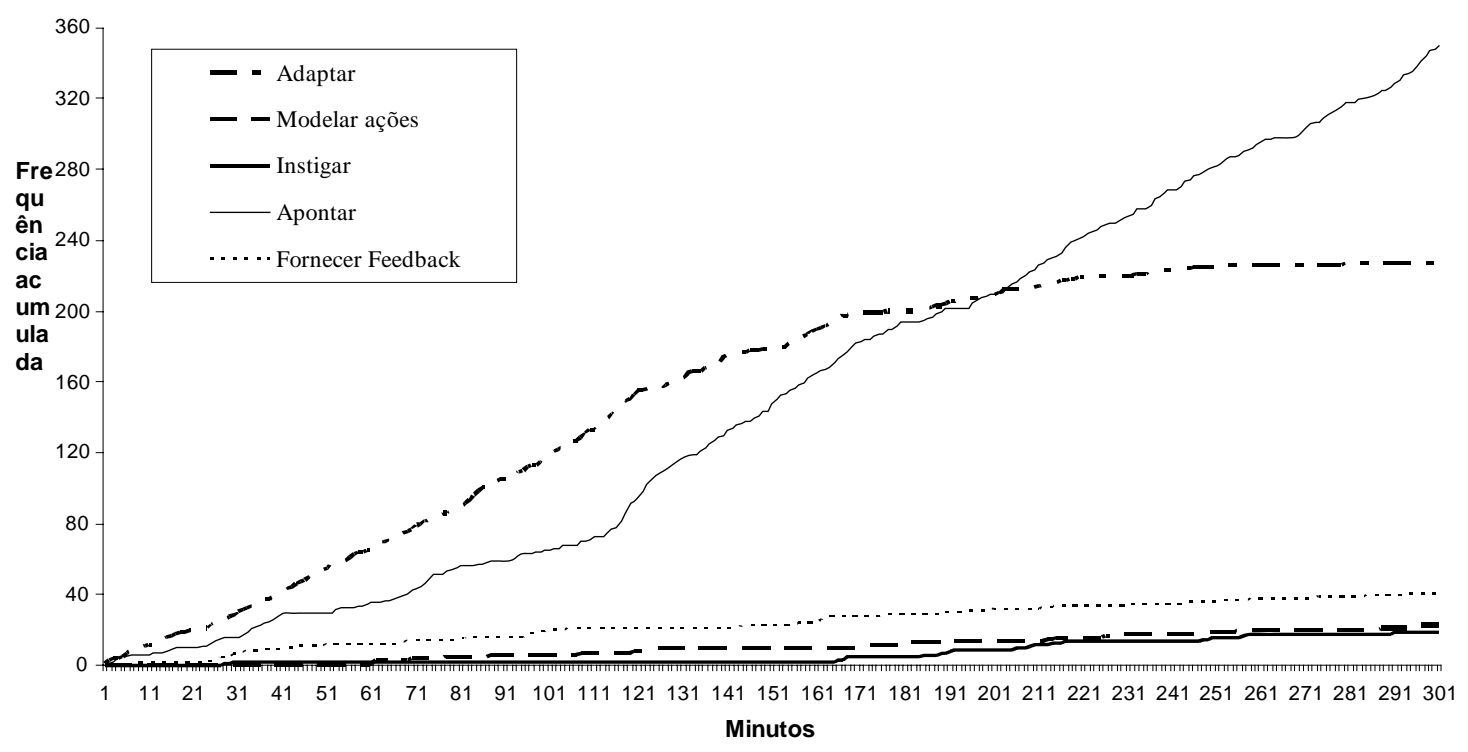

Figura 1. Freqüência acumulada das respostas de Estratégias de Ensino nas 21 sessões do Participante 1.

A Figura 2 apresenta as categorias 'módulos dinâmicos' e 'modo de episódio observar' da díade do Participante 1 em todas as sessões. Esta última catego- ria destacou-se das demais, apresentando uma freqüência acumulada de aproximadamente 300 emissões. Em seqüência vieram “Chorar”, "Interação mo- 
tora” e "Rir". Os comportamentos "Gritar" e "Gesti- (menos que 10). culação reativa” obtiveram freqüências muito baixas

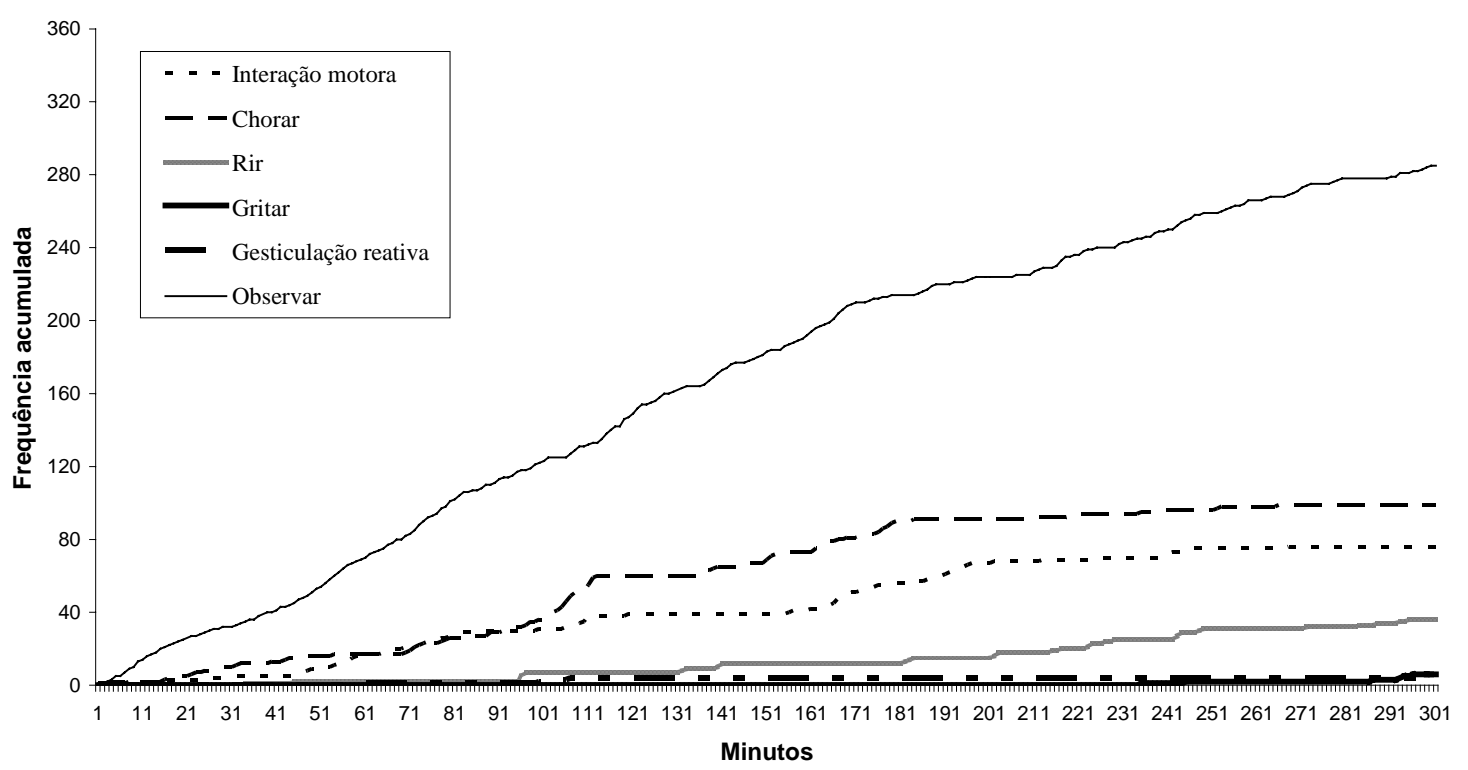

Figura 2. Freqüência acumulada de respostas nos Módulos Dinâmicos e Modo de Episódio nas 21 sessões do Participante 1.

A Figura 3 mostra as categorias 'interações protolingüísticas', 'aquisições cognitivas' e 'sons'. A categoria 'aquisições cognitivas' foi a mais emitida, apresentando um período inicial de poucas emissões (até 121 minutos), e posteriormente, uma freqüência acumulada crescente. O comportamento "Não-verbal do acompanhante” e a categoria 'sons' foram o segundo e terceiro mais emitidos. Os outros três comportamentos (referentes à categoria 'interações protolingüísticas') não apresentaram freqüências relevantes.

A Figura 4 mostra a categoria 'estratégias de ensino' da díade do Participante 2, em todas as suas sessões. Os comportamentos “Apontar" e "Adaptar” foram os mais emitidos, apresentando freqüências bem maiores do que os demais (acima de 150 emissões). Na seqüência encontra-se "Fornecer feedback", "Instigar" e "Modelar ações".

Na Figura 5 pode-se ver as categorias 'módulos dinâmicos' e 'modo de episódio' em todas as sessões da díade do Participante 2. O comportamento "Observar" aparece com a maior freqüência (acima de 120 emis- sões), seguido de "Rir" (acima de 40 emissões), "Interação motora" e "Chorar" (ambos abaixo de 40 emissões).

Na Figura 6 observa-se as emissões das categorias 'interações protolingüísticas', 'aquisições cognitivas' e 'sons' nas sessões da díade do Participante 2. Verifica-se que a categoria 'aquisições cognitivas' apresenta uma freqüência muito maior do que as demais (aproximadamente 160 emissões), sendo seguida das categorias 'sons' e "Não-verbal da criança com descrições da interação”. Os demais comportamentos referentes as 'interações protolingüísticas' apresentaram freqüências acumuladas abaixo de 10 ocorrências.

Na Figura 7 pode-se ver a freqüência acumulada da categoria 'estratégias de ensino' nas 15 sessões da díade do Participante 3. “Apontar”, com uma freqüência bem maior em relação às demais (acima de 240 emissões), foi seguido de "Adaptar" e "Fornecer feedback" (ambos com aproximadamente 80 emissões), e "Instigar" e "Modelar ações", que apresentaram cerca de 40 emissões. 


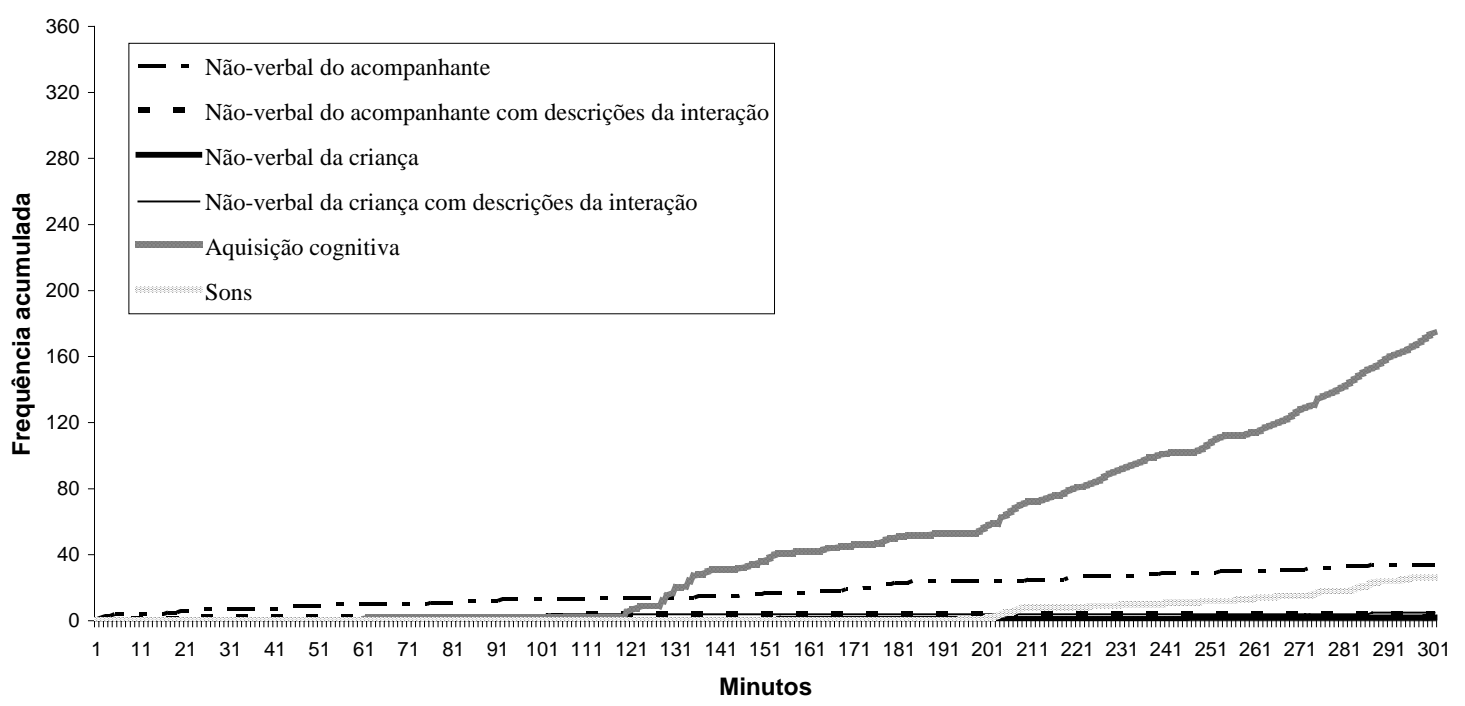

Figura 3. Freqüência acumulada de respostas de Interações Protolingüísticas, Aquisições Cognitivas e Sons nas 21 sessões do Participante 1.

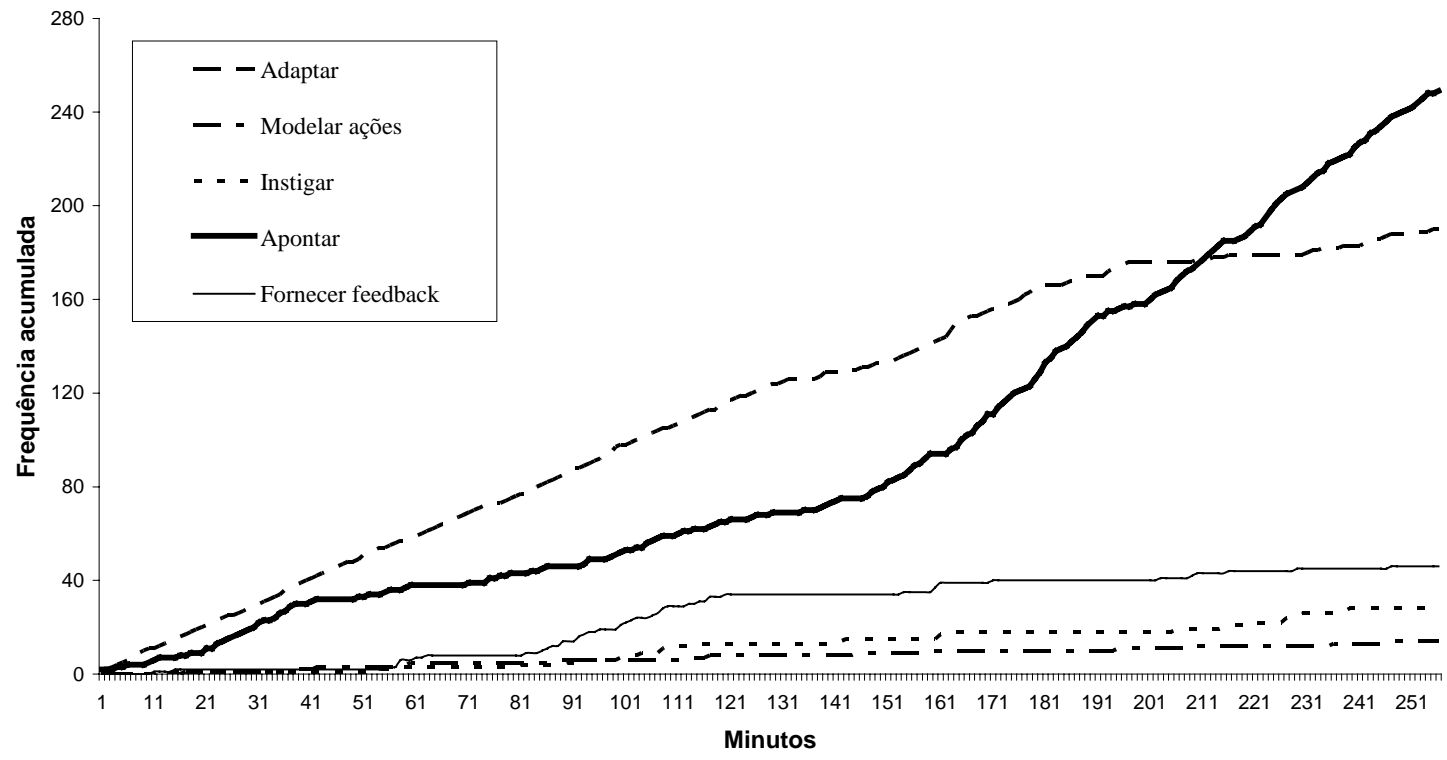

Figura 4. Freqüência acumulada das respostas de Estratégias de Ensino nas 17 sessões do Participante 2. 


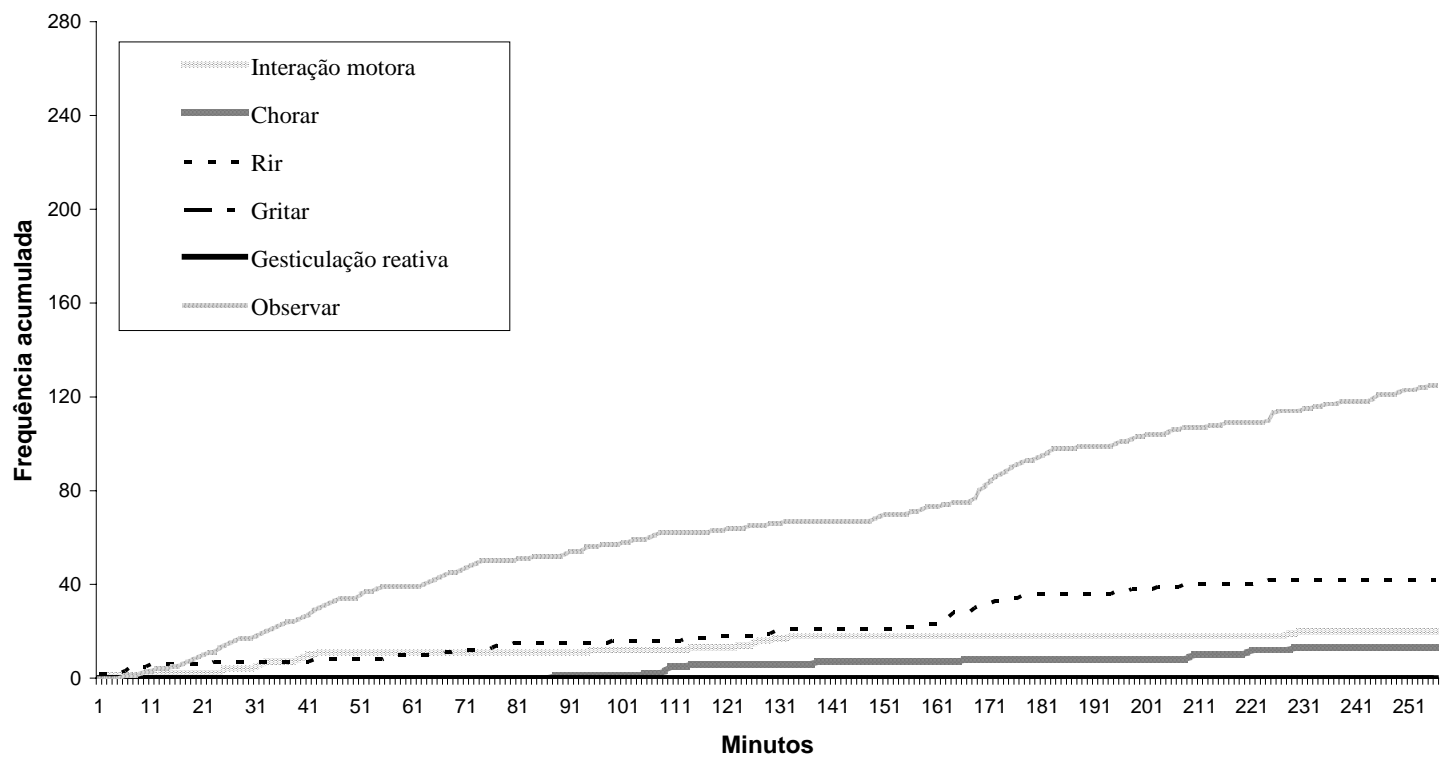

Figura 5. Freqüência acumulada de respostas nos Módulos Dinâmicos e Modo de Episódio nas 17 sessões do Participante 2.

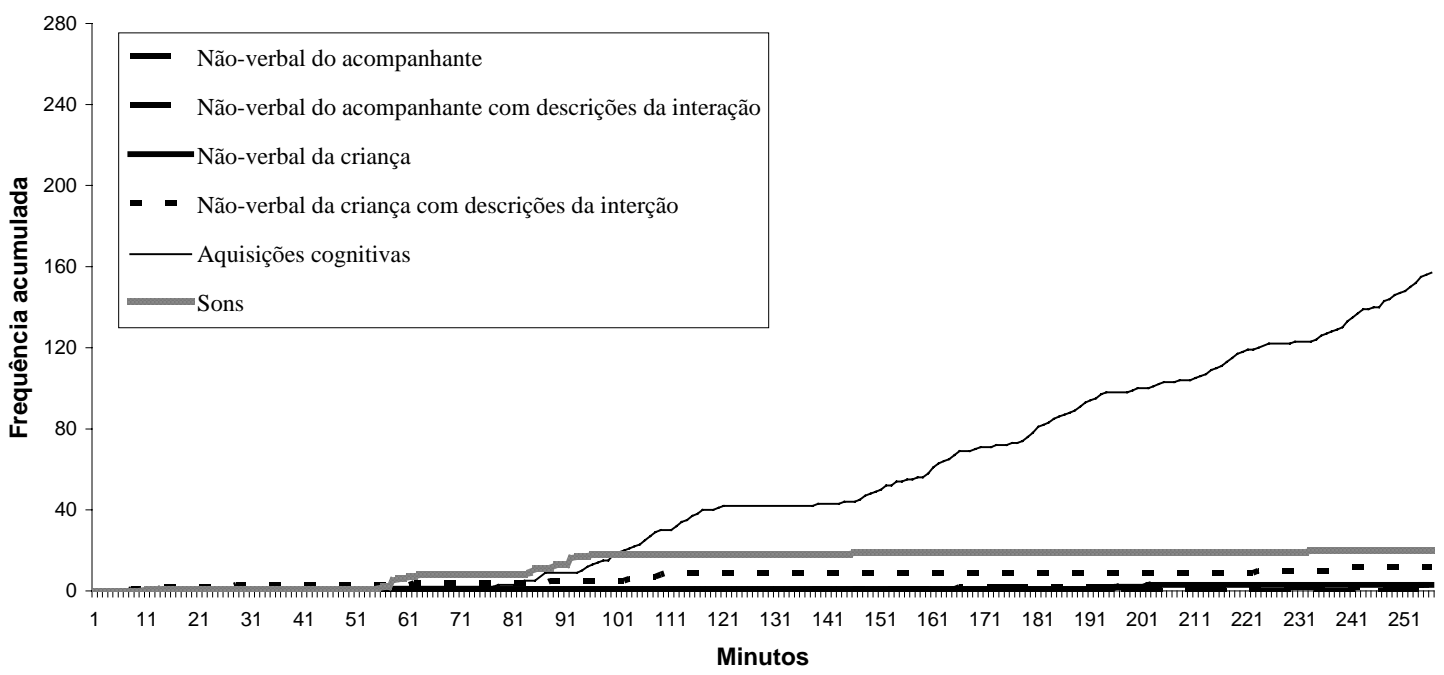

Figura 6. Freqüência acumulada de respostas de Interações Lingüísticas, Aquisições Cognitivas e Sons nas 17 sessões do Participante 2. 


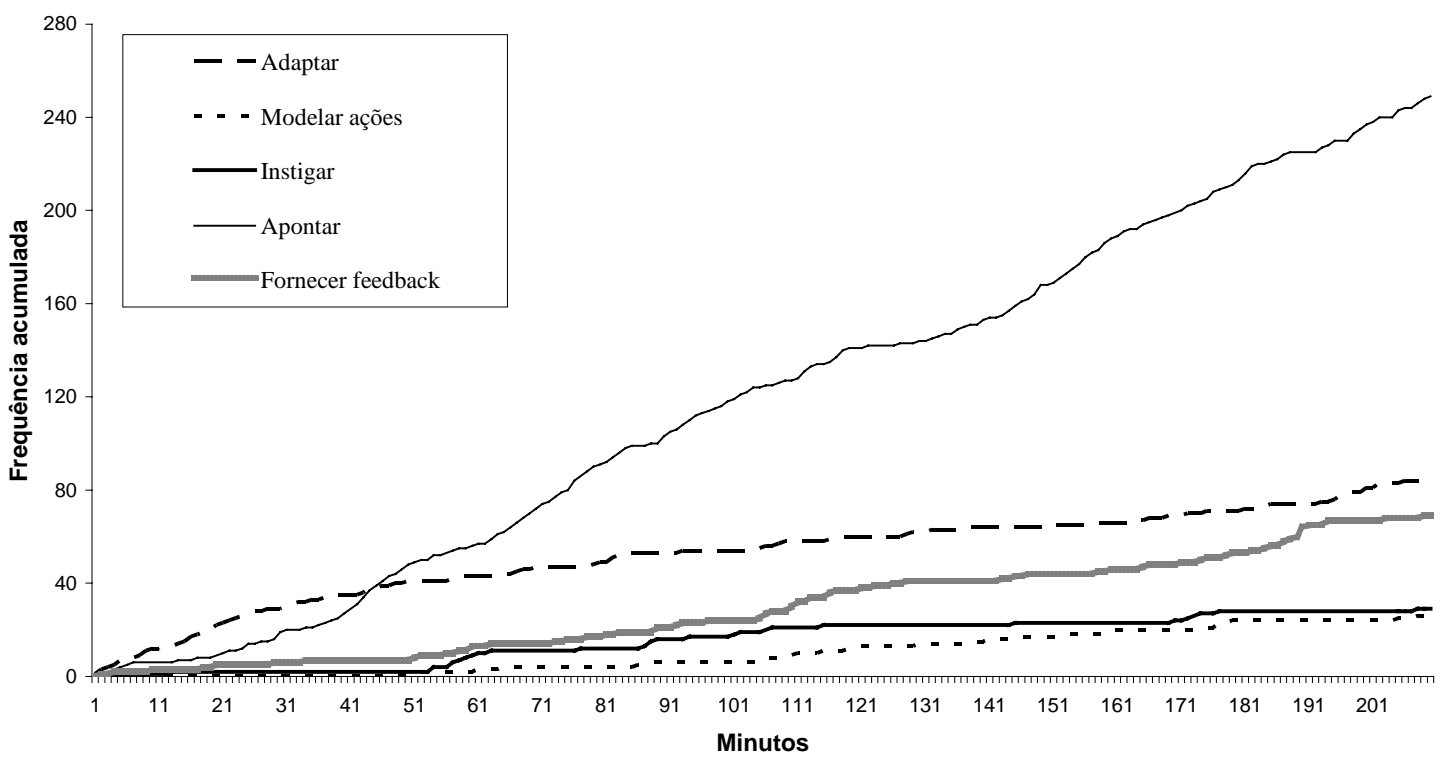

Figura 7. Freqüência acumulada das respostas de Estratégias de Ensino nas 15 sessões do Participante 3.

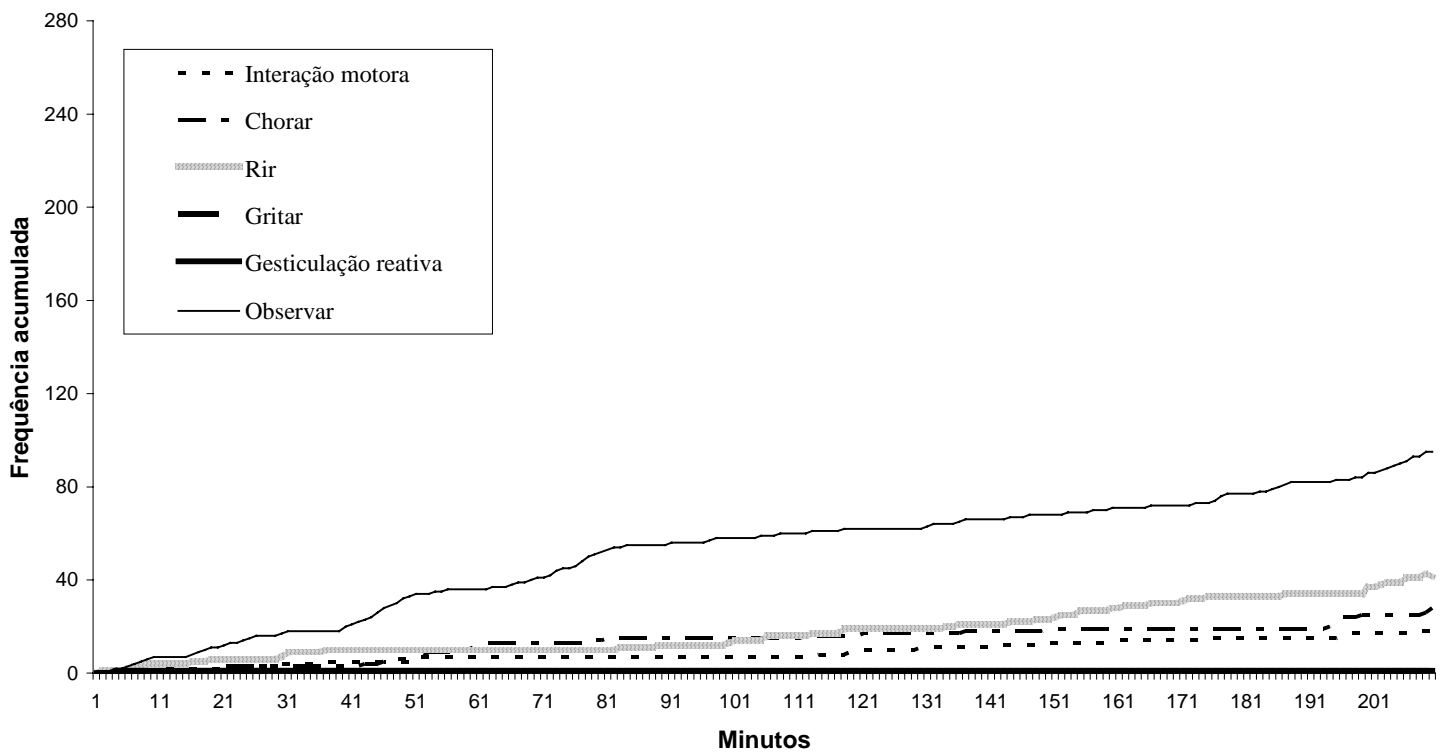

Figura 8. Freqüência acumulada de respostas nos Módulos Dinâmicos e Modo de Episódio nas 15 sessões do Participante 3. 


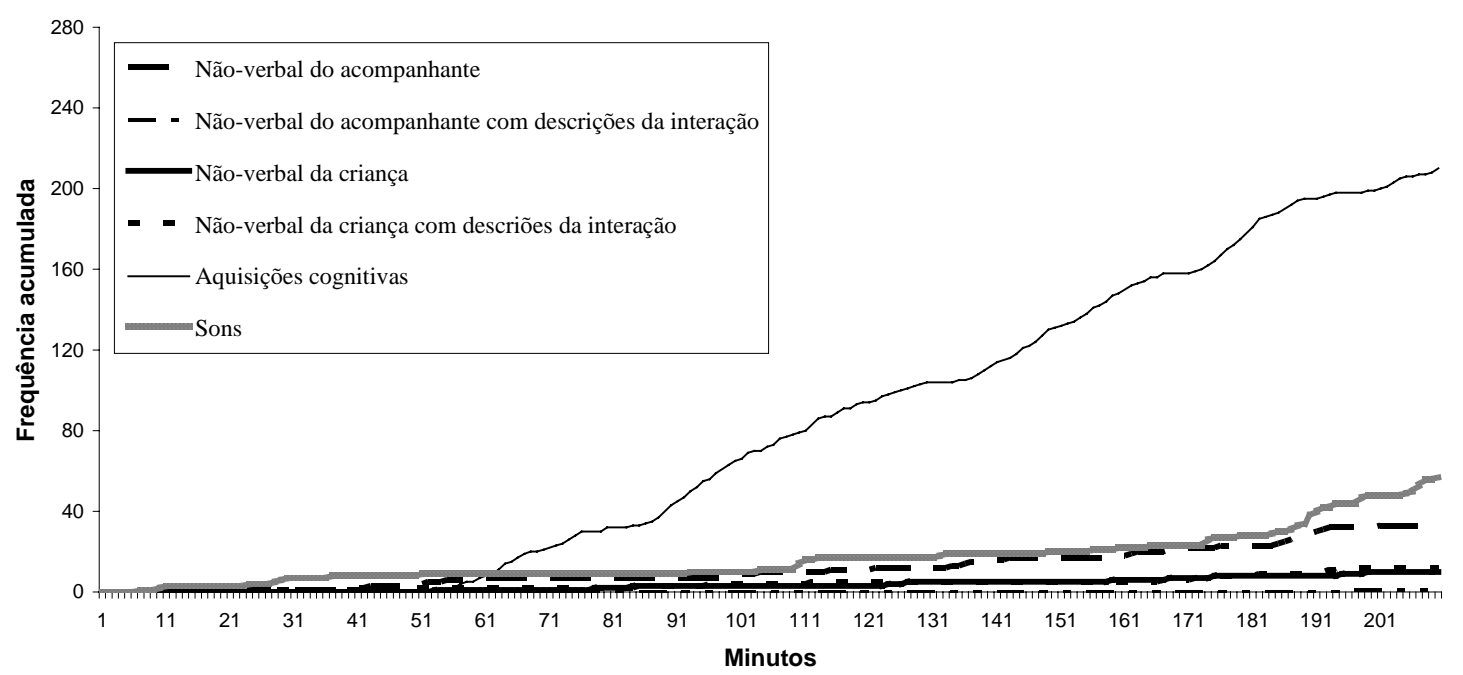

Figura 9. Freqüência acumulada de respostas de Interações Protolingüísticas, Aquisições Cognitivas e Sons nas 15 sessões do Particinante 3.

Na Figura 8 observam-se as categorias 'módulos dinâmicos' e 'modo de episódio' da díade do Participante 3. Os comportamentos mais emitidos foram "Observar", com uma freqüência acima de 80 emissões, "Rir", com aproximadamente 40 emissões, "Chorar" e "Interação motora", ambos com uma freqüência acumulada abaixo de 40.

A Figura 9 mostra as freqüências acumuladas das categorias 'interações protolingüísticas', ‘aquisições cognitivas' e 'sons' referentes a díade do Participante 3. A mais emitida foi a categoria 'aquisições cognitivas', apresentando uma freqüência acumulada muito maior do que as demais (acima de 200 emissões). 'Sons' foi a segunda mais emitida, com uma freqüência acumuladaa acima de 40 emissões, seguida de "Nãoverbal do acompanhante", "Não-verbal da criança”, e "Não-verbal da criança com descrições da interação" (sendo estas três últimas com freqüências acumuladas abaixo de 40 emissões).

\section{DISCUSSÃO}

Os resultados obtidos sobre os padrões comportamentais estabelecidos nas interações das díades são discutidos a seguir considerando as diferentes categorias selecionadas para análise neste estudo.

Com relação a categoria materna 'estratégias de ensino’ (Ver Figuras 1, 4 e 7), verificou-se altas freqüências, nas três díades, dos seguintes comporta- mentos: “Apontar” e “Adaptar”. Com freqüências menores, também para as três díades, observa-se "Fornecer feedback", "Modelar ações” e "Instigar". Estes comportamentos mostram os acompanhantes utilizando estratégias que podem auxiliar as crianças em aquisições e manutenções de seus comportamentos, replicando as análises de Moerk $(1990,1999)$.

A alta freqüência de “Apontar” mostra o acompanhante produzindo respostas que têm a probabilidade de aumentar a discriminabilidade das propriedades do mundo às quais ele está se referindo, aumentando a probabilidade da criança apresentar uma resposta de observação para o objeto/evento mencionado. Conforme mostrou a análise das variações paramétricas na variável 'direção do olhar para o referente' destas mesmas interações criança-acompanhante, feitas por Souza e Pontes (2007), este parece ser o caso. Parte-se da situação na qual o acompanhante observa os referentes (olhando/apontando para eles e/ou manipulando-os diretamente) e fala sobre eles, até as interações nas quais as respostas de observação do bebê são "mapeadas" pelo acompanhante de forma que este passa a falar dos objetos/ações que estão sendo observados pelo bebê. Este repertório de acompanhar as mudanças no foco do olhar do acompanhante representa um importante pré-requisito no processo de aquisição da 'linguagem' (Lyra, 2000; Lyra \& Chaves, 2000; Zamberlan, 2002). 
Já a freqüência de “Adaptar” se relaciona com o fato do acompanhante geralmente ajustar sua fala, em ritmo, extensão e entonação (dado não demonstrado) a um nível simplificado, comparado à fala adulta normal, quando interage com o bebê (Braz \& Salomão, 2002; Véras \& Salomão, 2005), o que parece contribuir para o surgimento de respostas de imitação vocal (Moerk, 1999; Souza, 2003).

A freqüência menor dos comportamentos "Fornecer feedback", "Modelar ações" e "Instigar" pode ser função do conjunto restrito de comportamentos não verbais, mas principalmente verbais (com os quais estas ‘estratégias de ensino' geralmente são empregadas) que os bebês emitem no seis meses iniciais de vida. Apesar de não ter apresentado uma freqüência tão alta, estes comportamentos têm grande importância nas interações, uma vez que, através deles, os acompanhantes modulam diretamente os comportamentos das crianças, auxiliando-as na aquisição dos seus repertórios comportamentais e ao mesmo tempo engajando-as nas interações (Braz \& Salomão, 2002; Mendes \& Seidl de Moura, 2004; Silva \& Salomão, 2002; Véras \& Salomão, 2005).

Analisando a categoria 'módulos dinâmicos' (Ver Figuras 2, 5 e 8), verificou-se que nas díades dos Participantes 2 e 3 o comportamento "Rir" foi o mais emitido, e na díade do Participante 1 foi "Chorar". Apenas o comportamento "Interação motora" ocorreu de maneira consistente nas três díades. Não ficou claro, no entanto, se estes comportamentos exerciam a função, esperada deles, de moduladores da extensão e ritmo da interação. Considerando que na literatura sobre interação mãe-bebê estes comportamentos têm sido interpretados como formas pelas quais um bebê pode responder a eventos do ambiente, podendo estabelecer um nível de "comunicação" (protoconversações) com seu acompanhante (Seidl de Moura e cols., 2004), pode ser que na continuidade desta linha de pesquisa estes comportamentos possam ser categorizados e analisados ou como 'aquisições cognitivas' ou como ‘interações protolingüísticas', procurando verificar como as 'estratégias de ensino' dos acompanhantes influenciam o seu estabelecimento e desenvolvimento.

A categoria 'modo de episódio' (Ver Figuras 2, 5 e 8), representada pelo comportamento filial "Observar”, obteve freqüências muito altas nas três díades. Este dado corrobora a informação da literatura que sugere que bebês, nos meses iniciais de vida, tendem a responder a estímulos ambientais através de comportamentos reativos (Ribes \& Quintana, 2003; Zamberlan,
2002). Este comportamento, por sua vez, tem sido considerado como a principal forma de participação do bebê nas interações proto-lingüísticas (protoconversações) (Silva \& Salomão, 2002).

As categorias 'aquisições cognitivas' e 'sons' (Ver Figuras 3, 6 e 9) também representam comportamentos filiais emitidos pelos três Participantes. A primeira, depois da categoria 'modo de episódio' foi a mais emitida pelos bebês, seguida de 'sons'. Ambas mostram que os bebês começam a responder ativamente aos estímulos que lhe são expostos de acordo com os ajustes funcionais decorrentes de suas interações (Ribes \& Quintana, 2003; Souza, 2003), aumentando a probabilidade de que possam interagir com seus acompanhantes através de balbucios e pela exploração sensorial de objetos (ver também Mendes \& Seidl de Moura, 2004).

Por último, os resultados da categoria 'interações protolingüísticas’ (Ver Figuras 3, 6 e 9) mostraram que a interação mais emitida nas díades dos Participantes 1 e 3 foi "Não-verbal do acompanhante" e na díade do Participante 2 "Não-verbal da criança com descrições da interação". Sendo que esta última interação também ocorreu nas díades dos Participantes 1 e 3 , só que com uma freqüência menor. Considerando o período durante os quais os bebês do presente estudo foram investigados (dos 2 aos 5-7 meses de vida), não surpreende que a maioria de suas interações nesta categoria tenham sido com base em morfologias nãoverbais (protoconversações). Por outro lado, estes dados revelam que mesmo durante este período, quando a criança não é tão responsiva verbalmente, o acompanhante interage verbalmente com ela de maneira significativa, fornecendo diversos pareamentos entre palavras e referentes, assim como modelos gramaticais corretos, elementos importantes na aquisição de repertórios lingüísticos (Souza, 2001, 2003; Tomasello, 2003). Pode-se ressaltar ainda que o padrão de interação verbal com o bebê parece estar relacionado ao conhecimento que os acompanhantes têm sobre as competências dos bebês: este conhecimento influencia na atribuição de significados às ações infantis por parte do acompanhante, o que, por sua vez, pode influenciar no tipo/qualidade da interação verbal estabelecida com a criança (Seidl de Moura e cols., 2004).

De maneira geral, os resultados da freqüência acumulada para as 'estratégias de ensino', 'aquisições cognitivas', 'sons', 'módulos dinâmicos' e 'modo de episódio' mostraram uma tendência para a ocorrência de covariações entre os comportamentos do acompanhante e os da criança: aumentos nos repertórios da 
criança geralmente estiveram correlacionados com aumentos nos comportamentos da categoria 'estratégia de ensino' do acompanhante. Considerando que no período de desenvolvimento das crianças estudadas neste trabalho é o acompanhante quem tem, geralmente, uma função mais ativa nas suas interações, estas covariações podem indicar que o comportamento do acompanhante estava sendo contingente, ou pelo menos contígüo, aos da criança.

No entanto, a análise minuto-a-minuto da interação criança-acompanhante, apesar de possibilitar detectar estas tendências a covariações, não permitiu analisar a ocorrência de relações contingenciais entre os comportamentos do acompanhante e os da criança (como o fez Moerk, 1990,1999). Para verificar se as tendências a covariações observadas neste estudo implicaram também em relações contingenciais entre comportamentos da criança e do acompanhante, as interações entre estes, filmadas para este estudo, devem ser reanalisadas, procurando-se agora realizar uma análise ainda mais molecular, buscando estabelecer um tipo de análise seqüencial como a desenvolvida por Moerk (1999).

\section{REFERÊNCIAS}

Bornstein, M. H., \& Tamis-LeMonda, C. S. (2004). Mother-infant interaction. Em G. Bremner \& A. Fogel (Orgs.), Blackwell handbook of infant development (p. 269-295). Oxford: Blackwell Publishing.

Braz, F. S., \& Salomão, N. M. R. (2002). A fala dirigida a meninos e meninas: Um estudo sobre o input materno e suas variações. Psicologia: Reflexão e Crítica, 15(2), 333-344.

Brino, A. L. F., \& Souza, C. B. A. (2005). Comportamento verbal: Uma análise da abordagem skinneriana e das extensões explicativas de Stemmer, Hayes e Sidman. Interação em Psicologia, 9, 253-262.

Lock, A. (2004). Preverbal communication. Em G. Bremner \& A. Fogel (Orgs.), Blackwell handbook of infant development (p. 379-403). Oxford: Blackwell Publishing.

Lyra, M. C. D. P. (2000). Desenvolvimento de um sistema de relações historicamente construído: Contribuições da comunicação no início da vida. Psicologia: Reflexão e Crítica, 13(2), 1-19.

Lyra, M. C. D. P., \& Chaves, E. C. (2000). O desenvolvimento da comunicação no início da vida: Estabelecimento, extensão e abreviação. Temas em Psicologia da SBP, 8(3), 225-240.

Mendes, D. M. L .F., \& Seidl de Moura, M. L. (2004). Desenvolvimento da brincadeira e linguagem em bebês de 20 meses. Psicologia: Teoria e Pesquisa, 20(3), 215-222.

Moerk, E. L. (1978). Relationships between parental input frequencies and children's language acquisition: A reanalysis of Brown's data. Journal of Child Language, 7, 105-118.
Moerk, E. L. (1983). A behavioral analysis of controversial topics in first language acquisition: Reinforcements, corrections, modeling, input frequencies, and the three-term contingency pattern. Journal of Psycholinguistic Research, 12, 129-155.

Moerk, E. L. (1990). Three-term contingency patterns in motherchild verbal interactions during first-language acquisition. Journal of the Experimental Analysis of Behavior, 54, 293-305.

Moerk, E. L. (1999). Sequential analysis, multiple controlling stimuli, and temporal patterning in first-language transmission. The Analysis of Verbal Behavior, 16, 63-80.

Ribes, E., \& Quintana, C. (2003). Mother-child linguistic interactions and behavioral development: A multidimensional observational. The Behavior Analyst Today, 3, 442-454.

Schafer, G., \& Plunkett, K. (1998). Rapid word learning by fifteen-month-olds under tightly controlled conditions. Child Development, 69, 309-320.

Seidl de Moura, M. L., Ribas, A. F. P., Seabra, K. C., Pessôa, L. F., Ribas, R. C., \& Nogueira, S. E. (2004). Interações iniciais mãe-bebê. Psicologia Reflexão e Crítica, 17, 295-302.

Silva, M. P. V., \& Salomão, N. M. R. (2002). Interações verbais e não-verbais entre mães-crianças portadoras de síndrome de Down e entre mães-crianças com desenvolvimento normal. Estudos em Psicologia, 7(2), 311-323.

Skinner, B.F. (1992). Verbal behavior. Acton, MA: Copley Publishing Group. (Original publicado em 1957)

Souza, C. B. A. (2001). Adquisición de competencias lingüísticas: Una propuesta de análisis funcional. Tese de doutorado nãopublicada, Centro de Estudios e Investigaciones en Comportamiento, Universidad de Guadalajara, Jalisco, México.

Souza, C. B. A. (2003). Uma proposta de análise funcional da aquisição da linguagem: Resultados iniciais. Interação em Psicologia, 7, 83-91.

Souza, C. B. A., \& Pontes, S. S. (2007). Variações paramétricas em pré-requisitos da linguagem: Estudo longitudinal das interações criança-acompanhante. Interação em Psicologia,11, 5570.

Trevarthen C., \& Aitken K. J. (2001). Infant intersubjectivity: Research, theory, and clinical applications. Journal of Child Psychology and Psychiatry and Allied Disciplines, 42, 3-48.

Tomasello, M. (2003). Constructing a language: A used-based theory of language acquisition. Cambrigde, MA: Harvard University Press.

Véras, R. M., \& Salomão, N. M. R. (2005). Interações entre díades mãe-criança que apresentam a linguagem expressiva típica e díades mãe-criança que apresentam a linguagem expressiva atrasada. Interação em Psicologia, 9, 165-176.

Woodward, A. L., Markman, E. M., \& Fitzsimmons, C. M. (1994). Rapid word learning in 13- and 18-month-olds. Developmental Psychology, 30, 553-566.

Zamberlan, M. A. T. (2002). Interação mãe-criança: Enfoques teóricos e implicações decorrentes de estudos empíricos. Estudos de Psicologia (Natal), 7(2), 1-14.

Recebido: 22/06/2006 Revisado: 26/03/2007 Aceito: 09/05/2007 
Notas:

${ }^{1}$ Pesquisa financiada pelo CNPq (Processo 403178/2003-7).

2 Segundo Skinner (1957/1992), podemos acrescentar ainda que os membros do grupo social devem ser 'falantes/ouvintes competentes', i.e., eles devem ser capazes de consequenciar adequadamente o comportamento verbal de um falante de seu grupo social/verbal.

\section{Sobre os autores:}

Carlos Barbosa Alves de Souza: Professor Adjunto 3 do Departamento de Psicologia Experimental da UFPA e do Programa de Pósgraduação em Teoria e Pesquisa do Comportamento da UFPA.

Luciana dos Reis Affonso: Bolsista de Iniciação Científica do CNPq.

Endereço para correspondência: Rod. Arthur Bernardes, 1650 - Cond. Alto de Pinheiros - Pratinha - CEP 66825-000 - Belém, PA. Endereço eletrônico: carlos.souza@pesquisador.cnpq.br 